\title{
Fracture Deformation Measurements during Grouting in Hard Rock
}

\author{
Johan Thörn ${ }^{1}$, Edward Runslätt ${ }^{2}$, Åsa Fransson ${ }^{3}$, Johan Funehag ${ }^{4}$, Gunnar Gustafson ${ }^{5}$ \\ ${ }^{1} \mathrm{Ph} . \mathrm{D}$. student, MSc. Chalmers University of Technology, Gothenburg, S-412 96 Sweden, \\ johan.thorn@chalmers.se \\ ${ }^{2}$ Geo consultant, MSc. Golder Associates, Stockholm Sweden P-O Box 20127 S-104 60, \\ Edward_Runslatt@golder.se \\ ${ }^{3}$ Professor, Ph.D. Chalmers University of Technology, Gothenburg, S-412 96 Sweden, \\ asa.fransson@chalmers.se \\ ${ }^{4}$ Researcher, Ph.D. Chalmers University of Technology, Gothenburg, S-412 96 Sweden, \\ johan.funehag@chalmers.se \\ ${ }^{5}$ Professor, Ph.D. Chalmers University of Technology, Gothenburg, S-412 96 Sweden, \\ gunnar.gustafson@chalmers.se
}

\begin{abstract}
When a fracture system in crystalline rock is grouted the rock mass may deform. Such deformations may reduce the grouting efficiency since new flow paths are opened. The work presented here show that deformations occur at hydraulic tests and grouting and that deformation can be measured and evaluated as stiffness from in situ tests. Deformation measurements, hydraulic testing, and grouting was conducted in spring 2010 in the Hallandsås tunnel and hydraulic testing in a service tunnel in Gothenburg (Runslätt and Thörn, 2010).

For measuring physical deformation recently developed equipment from Chalmers University of Technology was used. Deformations were measured seven times in the same borehole. Three measurements were during grouting, and the remaining four from water pressure tests. Most deformations occurred at pump pressures of 1-1.4 MPa, which is lower than the calculated normal rock stress. Stiffness has been evaluated in several ways, including a new method, (Fransson, et al., 2010). Generally the evaluated stiffness is lower in the Hallandsås tunnel than in the Gothenburg tunnel. The results show agreement with other in situ experiments.
\end{abstract}

\section{INTRODUCTION}

When grouting fracture systems in crystalline rock the grout is pumped with a substantial overpressure. The force that the pressurized grout induces onto the fracture surfaces may change the aperture and deform the rock mass. If one grouted fracture is deformed, the interaction between blocks in the rock mass may cause another fracture to close, open, or shear along its fracture plane. Such effects may reduce the grouting efficiency as new paths for water leakage are opened. The objective of the project behind this paper was to measure such deformations in situ. The deformation measurements were carried out in the Hallandsås tunnel, Sweden, which is a railway tunnel being constructed in low stress (Largest horizontal principal stress, $\sigma_{H} \approx 4 \mathrm{MPa}$ ) and highly fractured and water bearing gneiss. 
The tunnel is approximately $7 \mathrm{~m}$ wide and $9 \mathrm{~m}$ high and the grouting boreholes are $6 \mathrm{~m}$ long and inclined $40^{\circ}$.

The deformation measurements were conducted during water pressure tests, WPT and grouting with silica sol. Some comparative hydraulic tests were conducted in a small service tunnel ( 4 by $4 \mathrm{~m}$ ) under Gothenburg, in a sparsely fractured granodiorite $\left(\sigma_{H} \approx 10 \mathrm{MPa}\right)$.

For rock where horizontal stresses $\sigma_{H}$ and $\sigma_{h}$ are larger than the vertical stress, $\sigma_{v}$ a part of the rock mass in the wall of a horseshoe-shaped tunnel experiences stress relief, and is therefore more prone to grout induced deformations. This is the case for the tunnels studied here. Deformations that significantly increase the water conducting capacity of a fracture are expected when the grouting pressure exceeds the normal stress. This causes normal deformation. With the presence of shear stresses deformations can be expected at lower grouting pressures. A common post grouting pressure is $2 \mathrm{MPa}$, and for the stress relieved portion of the wall this proves sufficient to deform fractures in this region.

\section{THEORY}

Effective stress, defined according to Terzaghi (e.g. Terzaghi (1943)) (1), is the sum of the rock stress, $\sigma$, and the pore pressure, $p$, in our case regarded across a fracture. This can be used to calculate hydraulic normal fracture stiffness as a change of aperture, $\Delta b$, per change of effective stress, $\Delta \sigma^{\prime},(2)$.

$$
\begin{aligned}
& \sigma^{\prime}=\sigma-p \\
& k_{n}=\frac{\Delta \sigma^{\prime}}{\Delta b}=\frac{\Delta \sigma-\Delta p}{\Delta b} \rightarrow[\Delta \sigma=0] \rightarrow k_{n}=\frac{\Delta p}{\Delta b}
\end{aligned}
$$

The normal stiffness, $k_{n}$, of rock fractures has been discussed before (Bandis, et al., 1983) and (Goodman, 1974), these methods are based upon closure of joints. The initial part of such closure curves, where closure rate is high is here denoted stage B, and the stiffer part is denoted stage A, see Figure 1. Fransson, et al., (2010) suggests a method for stiffness evaluation that utilizes grouting data, where flow regime and fracture volume change are utilized. Central in the stiffness evaluations performed here is the effective stress, (1). The work described in this paper utilizes both physical measurements across a deforming rock volume and hydraulic normal stiffness derived from increased flow in in situ fractures, Figure 1. The stiffer behaviour of a closed joint (stage A) is obtained initially, before the fracture is separated.

A relation between storativity, $S$, and transmissivity, $T$, in granitic rock presented by Rhén, et al. (2008), (3), was in Fransson (2009) combined with a relation between storativity and stiffness, including gravity, $g$, and density of the fluid at hand, $\rho_{f}$ (Doe and Geier, 1990), (4), to form a relation between fracture normal stiffness and transmissivity, (5). Here this normal stiffness evaluation gets a superscript $S$, from storativity. Transmissivity is approximated by the specific capacity measured by the pump equipment, $Q / \Delta h$ (Fransson, 1999). 

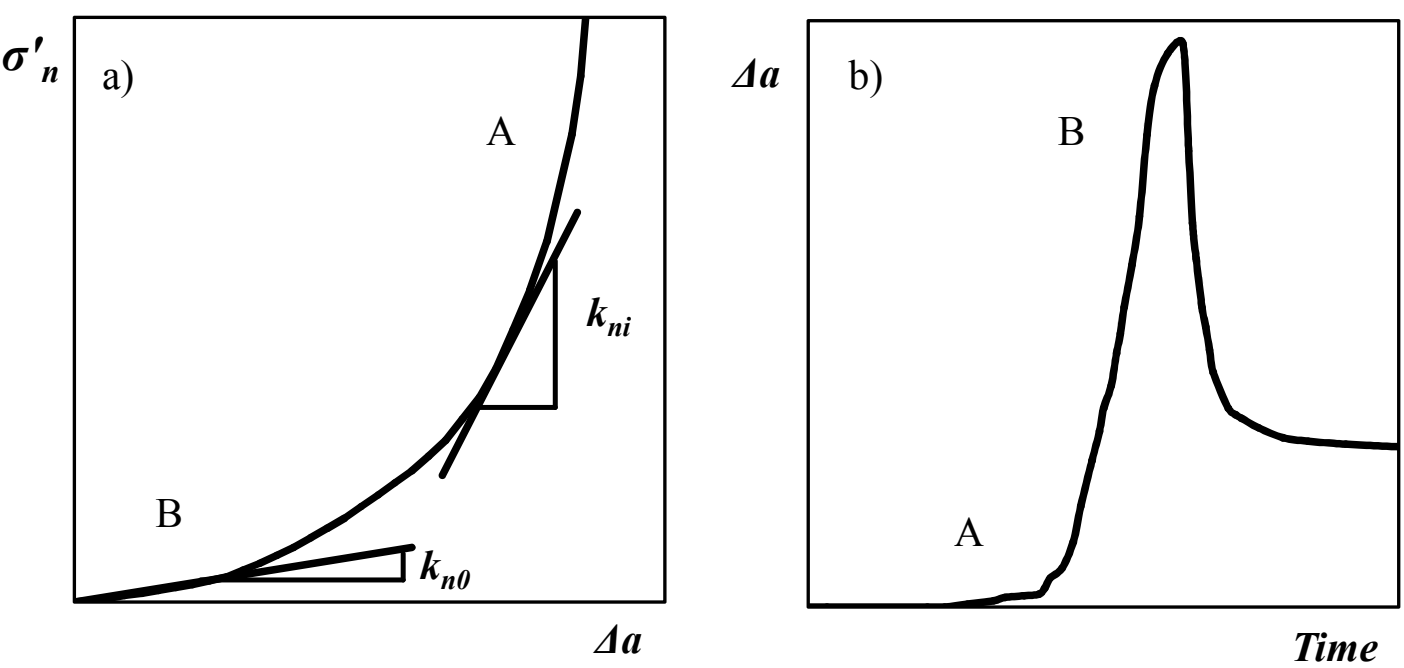

FIG. 1. a) A traditional closure curve (redrawn from Rutqvist and Stephansson, 2003). b) A deformation curve from this study, where a fracture is separated with increased pore pressure.

$$
\begin{aligned}
& S=0.0109 T^{0.71} \\
& S=\rho_{f} g\left(\frac{1}{k_{n}}\right) \\
& k_{n}^{S}=\frac{\rho_{f} g}{0.0109 T^{0.71}}
\end{aligned}
$$

An increased fluid pressure, $p$, results in a decreased effective stress, which in turn may cause opening of a fracture. The normal stiffness evaluated from changed aperture here is expressed as (2). A change in aperture in (2) can either be the measured physical deformation, $\Delta a$, or change in hydraulic aperture, $\Delta b$, evaluated according to the cubic law, (6), where $\mu$ is the viscosity of the fluid.

$$
b=\sqrt[3]{\frac{12 \cdot \mu \cdot T}{\rho \cdot g}}
$$

For the case of 2D flow Fransson, et al. (2010) approximates the pressure distribution from a grouted borehole to the grout spread front with a cone. The average pressure across the affected area is then equal to a third of the grouting overpressure, i.e. $\Delta p / 3$. This reduced value has been used in the numerator of (2) when calculating stiffness from change in hydraulic aperture, $k_{n}^{b},(7)$ and measured physical deformation, $k_{n}^{a}(8)$.

$$
k_{n}^{b}=\frac{\frac{\Delta p}{3}}{b_{2}-b_{1}}
$$




$$
k_{n}^{a}=\frac{\frac{\Delta p}{3}}{\Delta a_{2}-\Delta a_{1}}
$$

\section{MEASUREMENT METHOD FOR PHYSICAL APERTURE CHANGE}

Physical deformation measurements were conducted by logging displacement differences between the tunnel wall and a point at a certain depth in a borehole. The measurement equipment and test sequence are described below.

\section{Measurement Equipment}

An anchor was attached to a stainless steel rod that extended out of the borehole. The sum of deformations aligned with the rod, across the instrumented rock mass was measured relative to the wall. The rod was centered in the borehole with Teflon bushings, and compared to the friction against these, the rod can be considered stiff. The anchor was fastened to the borehole by three wings that can be extended when anchor is in position.

The measurements were conducted with an electric LVDT displacement gauge, logging deformation every second, with a resolution of approx. $1.6 \mu \mathrm{m}$, and an analog gauge with a resolution of $1 \mu \mathrm{m}$. The principal experimental setup can be seen in Figure 2, and the wall-part can be seen in Figure 3. For a more detailed description, see Runslätt and Thörn (2010).

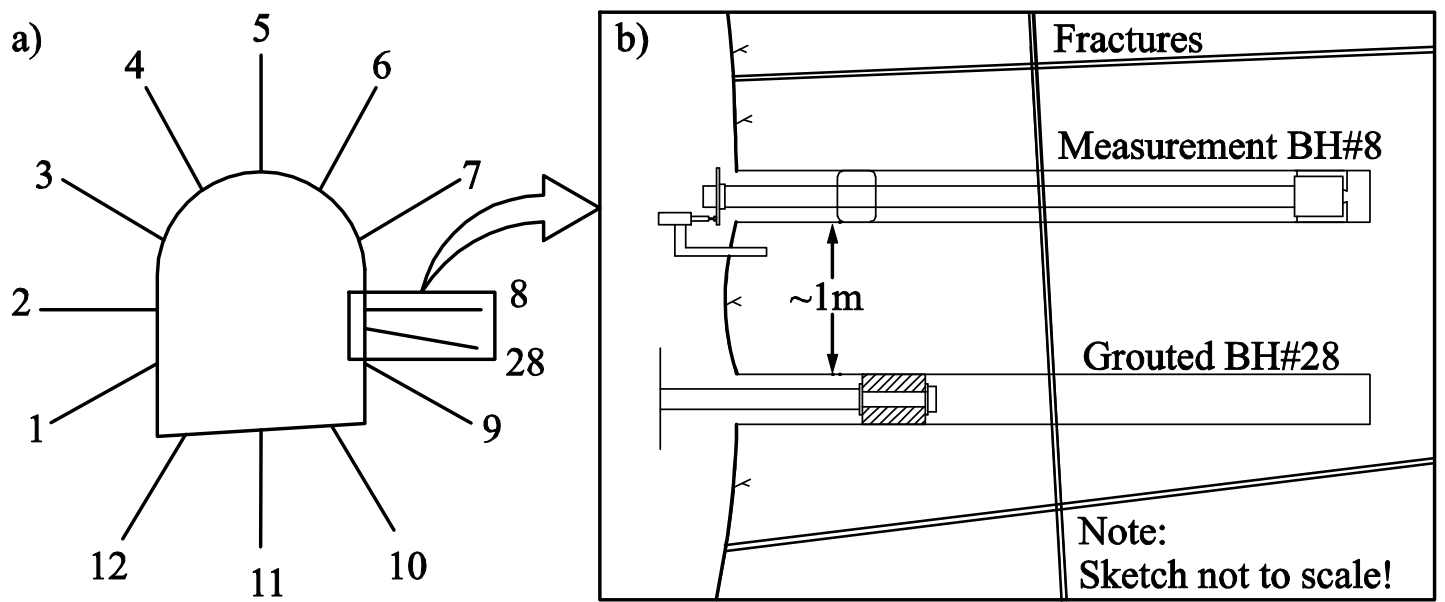

FIG. 2. a) The borehole geometry of first stage of a grouting fan in Hallandsås tunnel. b) Sketch of principle of deformation measurement. 

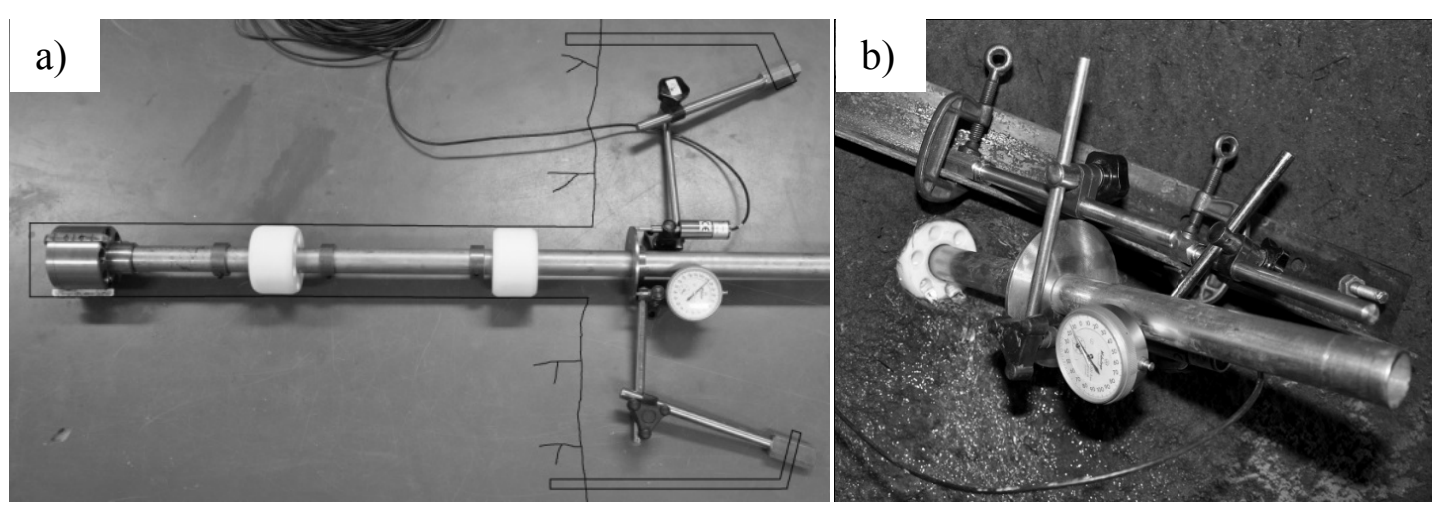

FIG. 3. a) Equipment schematically arranged. b) Equipment installed in BH8, Hallandsås tunnel.

\section{Measurement sequence}

The general sequence of hydraulic testing and deformation measurements was as follows: a) Natural inflow measured (NIT), for identifying a water conducting borehole to use. b) Drilling of a second borehole approximately $1 \mathrm{~m}$ away. c) Water pressure test (WPT) (with pressure measurement in the first borehole), for determining if there is a hydraulic contact between the two boreholes. d) WPT with deformation measurement in the first borehole (see Figure 2 and Figure 3 ). For a full step-to-step description, see Runslätt and Thörn (2010).

One WPT with pressure logging was conducted between borehole 28 , and borehole 8 in Hallandsås where the pressure measurements were conducted (step c, above). In total four WPT with deformation measurements (step d, above) were conducted between the same boreholes. Thereafter three boreholes, 9, 28 and 7 were grouted with silica sol while deformations were measured in borehole 8 . The fourth WPT was conducted with an anchor depth of $2 \mathrm{~m}$, and the remaining six tests had an anchor depth of $4.5 \mathrm{~m}$.

\section{RESULTS}

The measured deformations are presented in Figure 4 and 5. One graph is presented for each test where measured physical deformation, $\Delta a$ and change in hydraulic aperture in the grouted or injected borehole, $\Delta b(\mu \mathrm{m})$ are presented on the left vertical axis. Test time, $t$, is presented on the horizontal axis, and pump pressure, $\Delta p$ on the right vertical axis. 

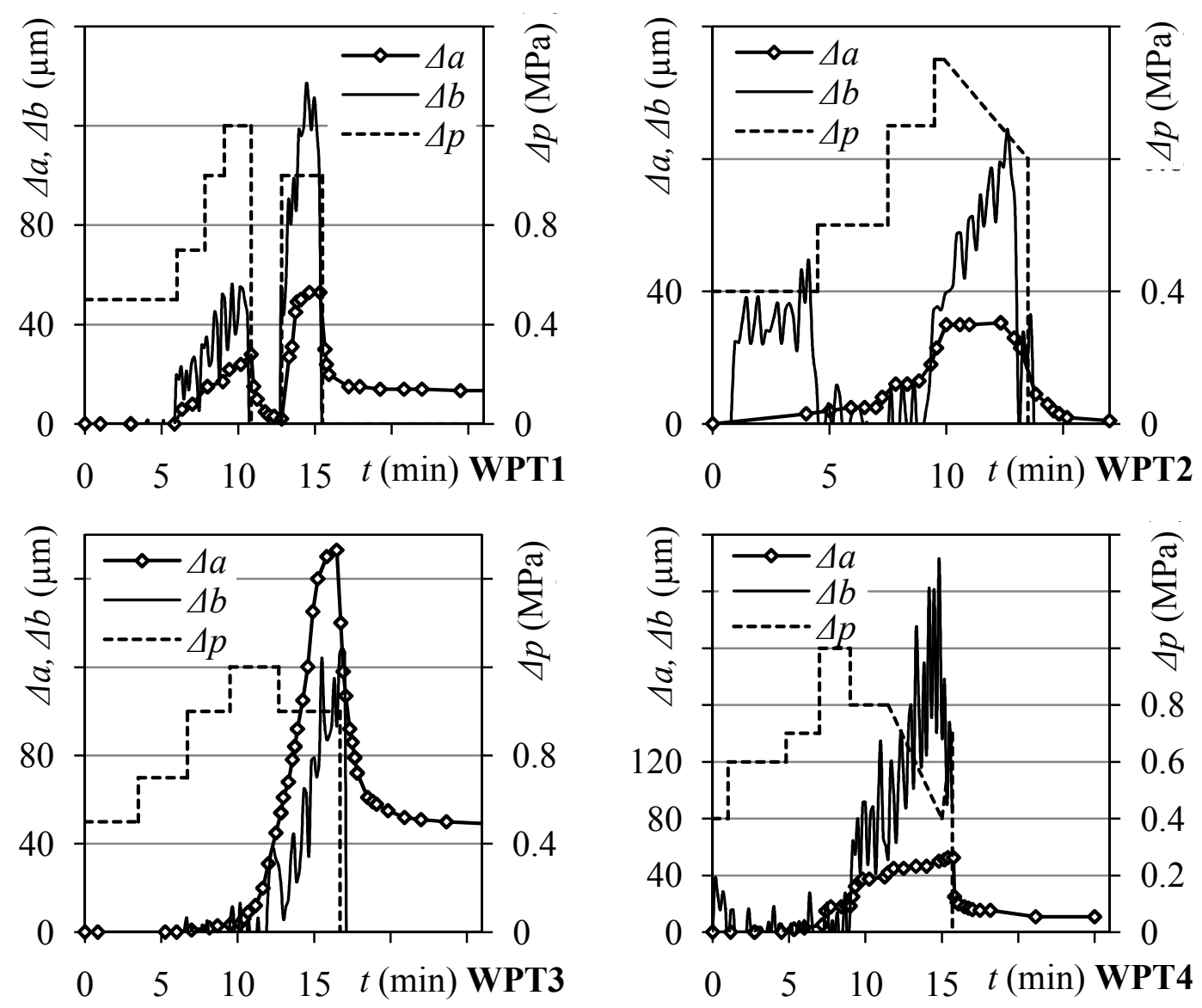

FIG. 4. a-d: deformation measurements in BH8 while performing WPT in BH28. The anchor was placed at $4.5 \mathrm{~m}$ in WPT1-3 and at $2 \mathrm{~m}$, just outside a transmissive fracture (at $2.1 \mathrm{~m}$ ), in WPT4.
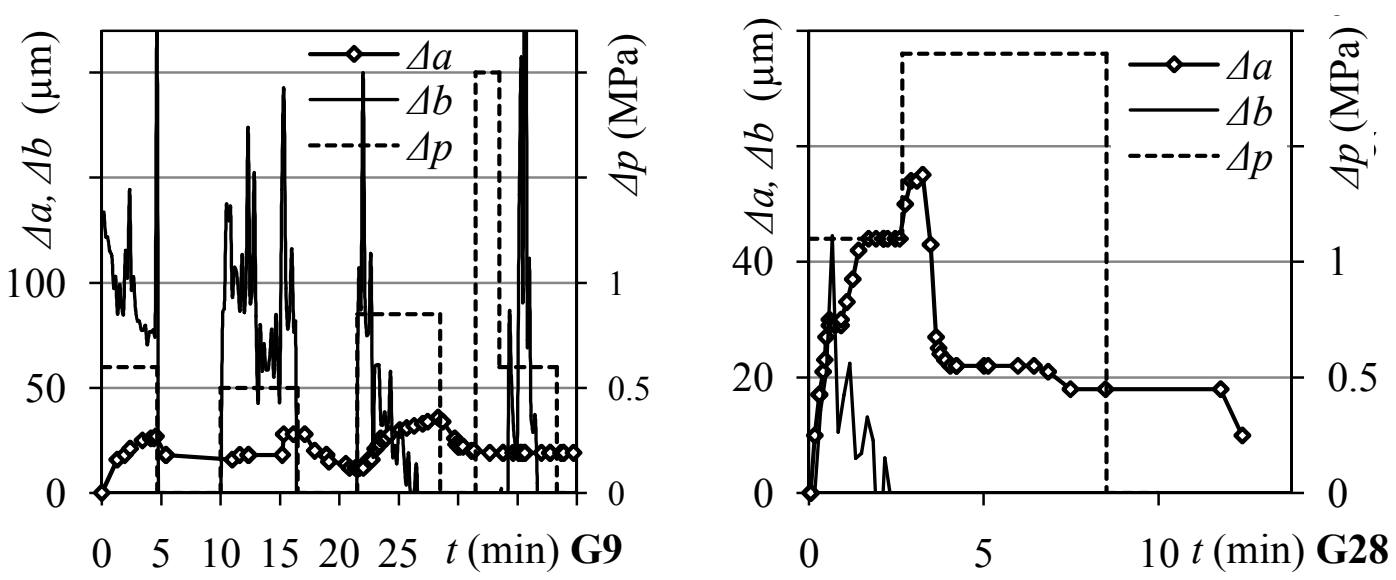

FIG 5. Continued on next page 


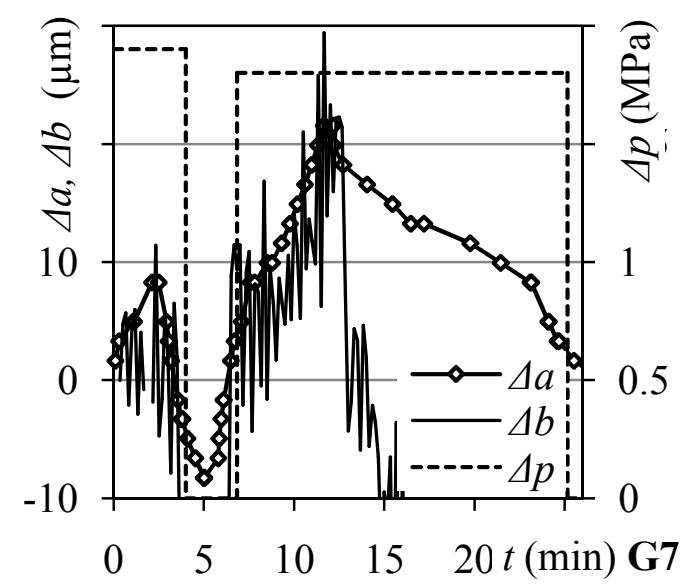

FIG. 5. a-c: Deformation in BH8 while grouting BH 9 (G9), BH28 (G28) and BH7 (G7). Since the grout is gelling in the fracture system the evaluated hydraulic apertures might be misleading. The gelling time of BH28 was 8 minutes, which probably can explain the behaviour of apertures and pressure during that test. The anchor was placed at $4.5 \mathrm{~m}$ for the three grout tests.

\section{ANALYSIS \\ Deformations}

The measurements of physical deformation are deemed robust. However, during the testing, water leakage, from the collar of the borehole into which water was injected, was observed. As the exact quantity of this leakage is unknown, the hydraulic data shall be regarded as approximate and only general conclusions drawn from it. Figure 6 presents a crossplot of physical and hydraulic aperture change from the stiffness intervals defined for the Hallandsås measurements.

The measured physical deformations, see Table 1, consisted of a resilient part, that regressed when the pressure was released and a permanent part that remained, see also curves in Figure 4. One explanation for this behavior could be normal deformations appearing resilient and shear deformations, resulting in the permanent part.

Table 1. Permanent and resilient physical deformations of the Hallandsås measurements.

\begin{tabular}{llllllll}
\hline Test & WPT1 & WPT2 & WPT3 & WPT4 & G-BH9 & G-BH28 & G-BH7 \\
\hline Distance to BH8 $(\mathrm{m})$ & 1 & 1 & 1 & 1 & 4 & 1 & 4 \\
Permanent $a(\mu \mathrm{m})$ & 14 & 0 & 48 & 11 & 19 & 18 & 0 \\
Resilient $a(\mu \mathrm{m})$ & 39 & 31 & 125 & 42 & 17 & 37 & 30 \\
Total $a(\mu \mathrm{m})$ & 53 & 31 & 173 & 53 & 36 & 55 & 30 \\
\hline
\end{tabular}




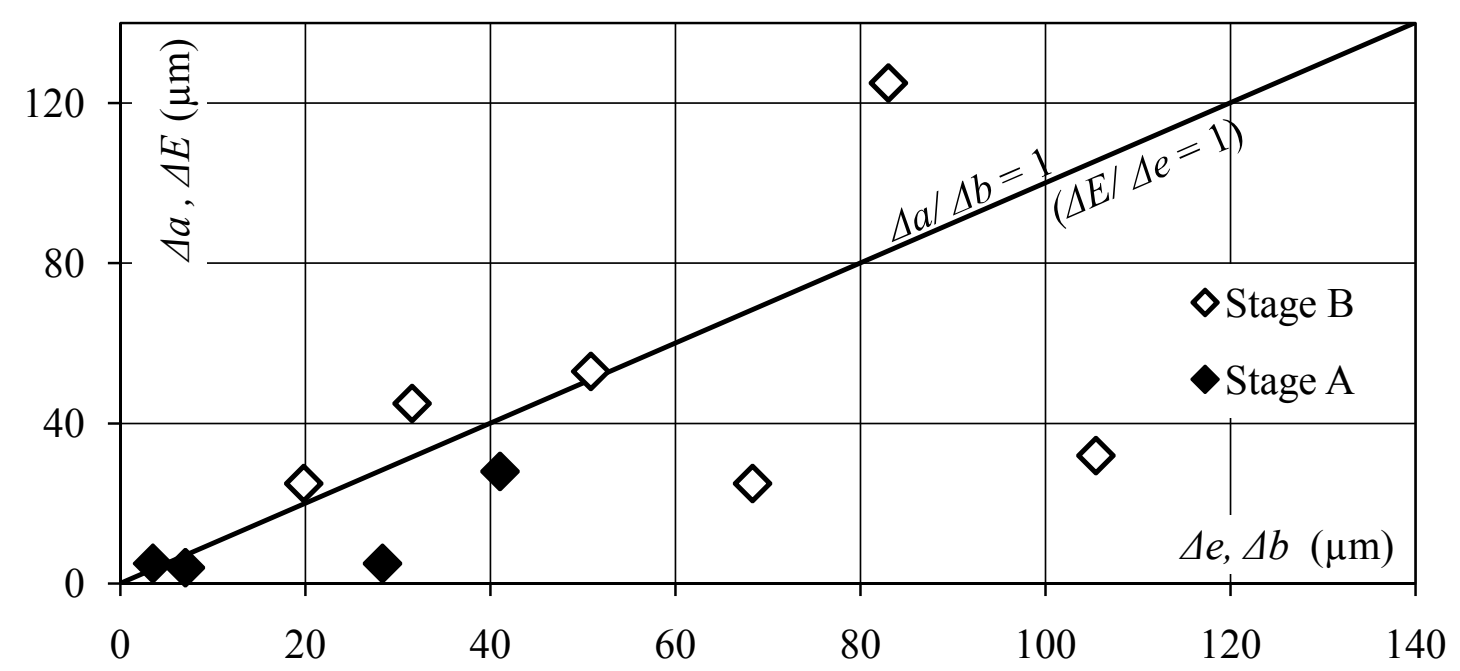

FIG. 6: Crossplot of change in hydraulic aperture and measured physical deformation. To help the reader the notations used by Barton and others have been added (compare to e.g. fig 3 in Olsson \& Barton, 2001).

\section{Stiffness}

Logging of pressure, pumped volume and time during the tests in Hallandsås, together with deformation logging enables the analysis of fracture stiffness. In Table $3 \Delta a$ is measured as described above, $\Delta p$ is logged from the pump, $b_{1}$ and $b_{2}$ are evaluated from pump flow through $Q / d h$ and cubic law (6) where the viscosity of the fluid, $\mu$, is set to $1.3 \cdot 10^{-3}$ Pas for water, and $5.5 \cdot 10^{-3}$ Pas for ungelled silica sol; density, $\rho$, is set to $1000 \mathrm{~kg} / \mathrm{m}^{3}$ for water and $1300 \mathrm{~kg} / \mathrm{m}^{3}$ for silica sol.

The different $k_{n}$-values are evaluated as in (5), (7) and (8). WPT results from the Gothenburg tunnel is presented in Table 2. The $k_{n}$-values from Table 2 and 3 are plotted as a line between $b_{1}$ and $b_{2}$ in Figure 7. In Figure 7 the fracture normal stiffness data compilation performed by (Fransson, 2009) is inserted.

Table 2. Compilation of stiffness data from the Gothenburg tunnel.

\begin{tabular}{crrrrrrr}
\hline BH & $\begin{array}{r}\text { Test } \\
\text { Unit: }\end{array}$ & $\begin{array}{r}\Delta p \\
(\mathrm{MPa})\end{array}$ & $\begin{array}{r}b_{1} \\
(\mu \mathrm{m})\end{array}$ & $\begin{array}{r}b_{2} \\
(\mu \mathrm{m})\end{array}$ & $\begin{array}{r}k_{n}{ }^{b} \\
(\mathrm{GPa} / \mathrm{m})\end{array}$ & $\begin{array}{r}k_{n}{ }^{S}, 1 \\
(\mathrm{GPa} / \mathrm{m})\end{array}$ & $\begin{array}{r}k_{n}{ }^{S}, 2 \\
(\mathrm{GPa} / \mathrm{m})\end{array}$ \\
& $\begin{array}{rrrrr}(6) \\
\text { Equation \#: }\end{array}$ & - & $(6)$ & $(6)$ & $(7)$ & $(5)$ & $(5)$ \\
\hline $\mathrm{KBH} 2$ & WPT & 0.5 & 26 & 29 & 45.9 & 404.2 & 308.9 \\
$\mathrm{KBH} 3$ & WPT & 2.0 & 19 & 30 & 61.9 & 744.2 & 295.5 \\
\hline
\end{tabular}


Table 3. Compilation of calculated stiffness data from the Hallandsås tunnel. The index numbers 1 and 2 for $b$ and $k_{n}{ }^{S}$ refer to start and end of the interval for which the stiffness is evaluated.

\begin{tabular}{|c|c|c|c|c|c|c|c|c|c|c|}
\hline \multirow[t]{3}{*}{$\mathrm{BH}$} & \multirow{2}{*}{\multicolumn{2}{|c|}{$\begin{array}{r}\text { Test Stage } \\
\text { Unit: }\end{array}$}} & $\Delta p$ & $b_{1}$ & $b_{2}$ & $\Delta a$ & $k_{n}^{b}$ & $k_{n}^{a}$ & $k_{n}^{S}, 1$ & $k_{n}^{S}, 2$ \\
\hline & & & Pa) & $(\mu \mathrm{m})$ & $\mu \mathrm{m})$ & $\mu \mathrm{m})$ & $\mathrm{Pa} / \mathrm{m})$ & $\mathrm{a} / \mathrm{m})$ & $\mathrm{a} / \mathrm{m})$ & $\mathrm{a} / \mathrm{m})$ \\
\hline & \multicolumn{2}{|c|}{ Equation \#: } & - & (6) & (6) & - & (7) & (8) & (5) & (5) \\
\hline \multirow[t]{2}{*}{28} & \multirow[t]{2}{*}{ WPT } & $\mathrm{A}$ & 0.9 & 110 & 128 & $-{ }^{\mathrm{a}}$ & 16.3 & $-{ }^{a}$ & 18.7 & 13.4 \\
\hline & & B & 1.2 & 138 & 236 & $-{ }^{\mathrm{a}}$ & 4.1 & $-{ }^{a}$ & 11.4 & 3.7 \\
\hline \multirow[t]{2}{*}{28} & \multirow[t]{2}{*}{ WPT1 } & A & 0.8 & 231 & 272 & 28 & 6.6 & 9.6 & 3.8 & 2.7 \\
\hline & & B & 1.0 & 266 & 317 & 53 & 6.8 & 6.5 & 2.8 & 1.9 \\
\hline \multirow[t]{2}{*}{28} & \multirow[t]{2}{*}{ WPT2 } & A & 0.3 & 292 & 320 & 5 & 4.0 & 22.7 & 2.3 & 1.9 \\
\hline & & B & 0.8 & 296 & 316 & 25 & 14.0 & 11.1 & 2.3 & 2.0 \\
\hline \multirow[t]{2}{*}{28} & \multirow[t]{2}{*}{ WPT3 } & A & 1.0 & 202 & 209 & 4 & 45.2 & 79.2 & 5.1 & 4.7 \\
\hline & & B & 1.0 & 209 & 292 & 125 & 3.9 & 2.6 & 4.8 & 2.3 \\
\hline \multirow[t]{2}{*}{28} & \multirow[t]{2}{*}{ WPT4 } & A & 0.6 & 247 & 250 & 5 & 52.0 & 36.7 & 3.3 & 3.2 \\
\hline & & B & 0.8 & 220 & 325 & 32 & 2.6 & 8.6 & 4.3 & 1.8 \\
\hline 9 & Grouting & B & 0.4 & 470 & 417 & 27 & $(-2.5)$ & 4.9 & $-{ }^{b}$ & $-b$ \\
\hline 28 & Grouting & B & 0.9 & 283 & 314 & 45 & 9.4 & 6.6 & $-b$ & $-b$ \\
\hline 7 & Grouting & $\mathrm{B}$ & 1.4 & 51 & 119 & 25 & 6.8 & 18.5 & $-^{b}$ & $-\mathrm{b}$ \\
\hline
\end{tabular}

${ }^{a}$ Pressure logged instead of deformation at this test

${ }^{\mathrm{b}}$ Only valid for water; this was a grouting test

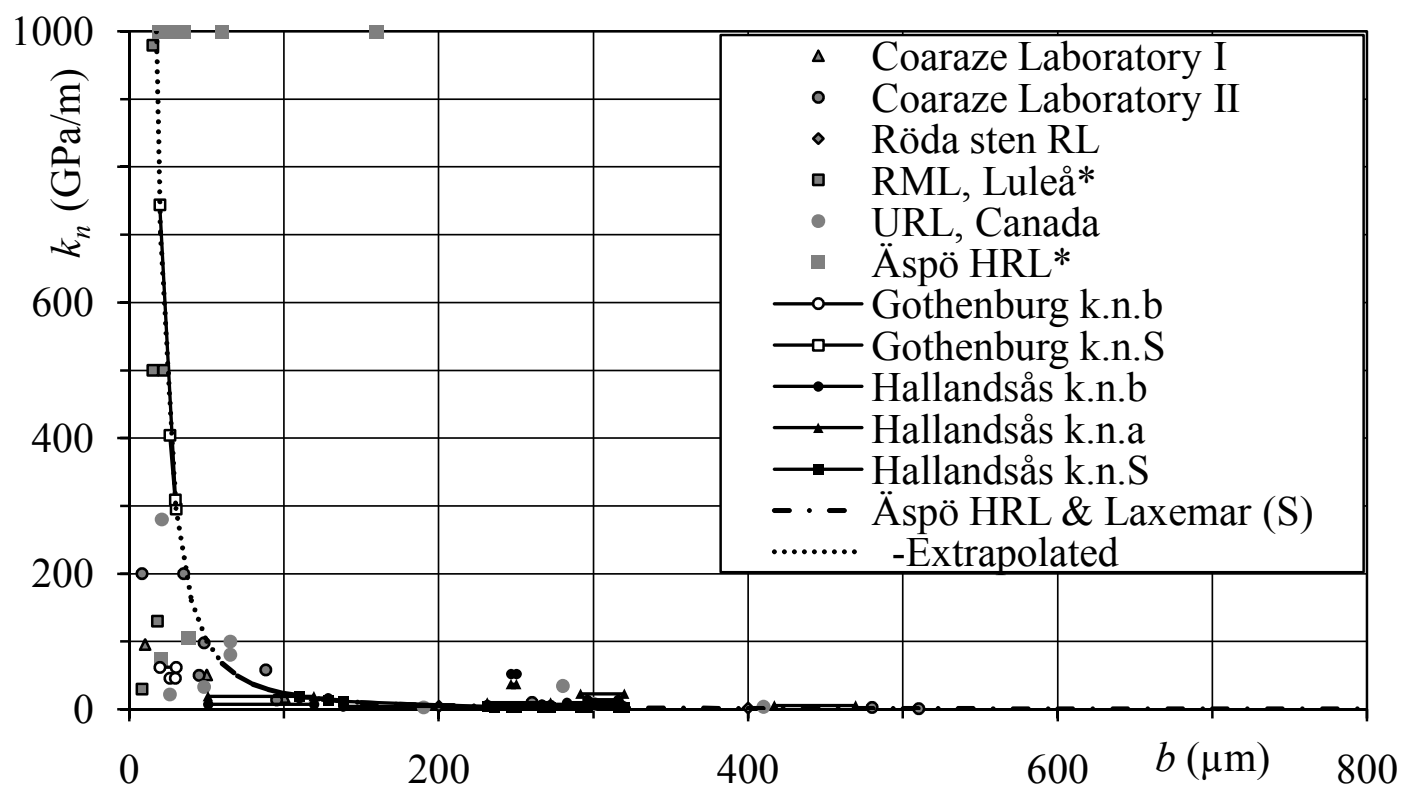

FIG. 7. Compilation of stiffness data from the tunnels and data as presented by Fransson (2009). The stiffness has been drawn across the aperture change that is basis for stiffness evaluation ( $b_{1}$ and $b_{2}$ in Table 1$)$ 


\section{CONCLUSIONS}

The test setup presented in this paper is relatively inexpensive and proved easy to use, and provided basis for stiffness estimates that is comparable to previously published data. The fracture stiffness in the low-stress Hallandsås tunnel was lower than in the higher-stress Gothenburg tunnel. Both permanent and resilient deformations were measured at the low pressures used in the post grouting.

\section{ACKNOWLEDGMENTS}

The financial support from the Swedish Nuclear Fuel and Waste Management Co, SKB is acknowledged. The help from Aaro Pirhonen and Peter Hedborg in building and tuning the equipment is also sincerely acknowledged.

\section{REFERENCES}

Bandis, S. C., Lumsden, A. C., and Barton, N. R. (1983). "Fundamentals of Rock Joint Deformation." Int J Rock Mech Min Sci Geomech Abstr, 20(6), 249-268.

Doe, T. W., and Geier, J. E. (1990). "Interpretations of Fracture System Geometry Using Well Test Data." SKB Stripa Project TR 91-03, Svensk Kärnbränslehantering $A B$.

Fransson, Å. (1999). "Grouting Predictions Based on Hydraulic Tests of Short Duration: Analytical, Numerical and Experimental Approaches." Thesis for Licentiate of Engineering., Chalmers University of Technology, Gothenburg.

Fransson, Å. (2009). "Literature survey: Relations between stress change, deformation and transmissivity for fractures and deformation zones based on in situ investigations. SKB R-09-13."

Fransson, A., Tsang, C. F., Rutqvist, J., and Gustafson, G. (2010). "Estimation of deformation and stiffness of fractures close to tunnels using data from single-hole hydraulic testing and grouting." Int J Rock Mech Min Sci, 47(6), 887-893.

Goodman, R. E. "The mechanical properties of joints." Proc., Proceedings of the 3rd Int. Congr. International Society of Rock Mechanics, National Academy of Sciences, Washington, DC, 127-140.

Olsson, R., \& Barton, N. (2001). "An improved model for hydromechanical coupling during shearing of rock joints." Int J Rock Mech Min Sci, 38(3), 317-329.

Rhén, I., Forsmark, T., Hartley, L., Jackson, P., Roberts, D., Swan, D., and Gylling, B. (2008). "Hydrogeological conceptualisation and parameterisation, Site descriptive modelling SDM-Site Laxemar, SKB R-08-78."

Runslätt, E., and Thörn, J. (2010). "Fracture deformation when grouting in hard rock: In situ measurements in tunnels under Gothenburg and Hallandsås."MSc. Thesis, Chalmers University of Technology, Gothenburg.

Rutqvist, J., and Stephansson, O. (2003). "The role of hydromechanical coupling in fractured rock engineering." Hydrogeology Journal, 11(1), 7-40.

Terzaghi, K. (1943). Theoretical soil mechanics. New York: Wiley 